28. Akhnazarova, S. and Kefarov, V., Experiment Optimization in Chemistry and Chemical Engineering, Mir Publishers, Moscow, Russia, 1982

29. Zhu, Z., Zhang, G., Luo, Y., Ran, W. and Shen, Q., Production of lipopeptides by Bacillus amyloliquefaciens XZ-173 in solid state fermentation using soybean flour and rice straw as the substrate. Bioresour. Technol., 2012, 112, 254-260; doi:10.1016/j.biortech. 2012.02.057.

30. Box, G. E. and Wilson, K., On the experimental attainment of optimum conditions. J. R. Stat. Soc. Series. B, 1951, 13, 1-45.

31. Saibaba, K. V. N. and King, P., Modelling and optimization of dye removal process using hybrid response surface methodology and genetic algorithm approach. J. Fundam. Renew. Energy Appl., 2014, 4(01), doi:10.4172/2090-4541.1000126.

32. Shirodkar, P. V. and Muraleedharan, U. D., Enhanced $\alpha$-amylase production by a marine protist, Ulkenia sp. using response surface methodology and genetic algorithm. Prep. Biochem. Biotechnol., 2017, 47(10), 1043-1049; doi:10.1080/10826068.

ACKNOWLEDGEMENT. We thank the Head, Department of Biotechnology, Goa University for providing funds and facilities.

Received 26 March 2019; revised accepted 20 June 2019

\section{South Asian subtropical low-level jet: influence on regional hydrology and aerosol optical depth}

\author{
T. R. Anoop ${ }^{1}$, C. K. Unnikrishnan ${ }^{1, *}$, \\ Karumuri Ashok ${ }^{2}$, K. K. Ramachandran ${ }^{1}$ and \\ T. N. Prakash ${ }^{1}$ \\ ${ }^{1}$ National Centre for Earth Science Studies, Akkulam, \\ Thiruvananthapuram 695011 , India \\ ${ }^{2}$ University of Hyderabad, Central University P.O., \\ Prof. C.R. Rao Road, Gachibowli, Hyderabad 500 046, India
}

A 38-year high-resolution wind climatology shows consistent occurrence of hitherto unreported South Asian subtropical low-level jets (SASLLJs) over the $31^{\circ}-35^{\circ} \mathrm{N}$ and $60^{\circ}-62^{\circ} \mathrm{E}$ latitude-longitude region, occurring throughout the year are the northerly $L L J$ (NLLJs) and southerly LLJs (SLLJs). The NLLJ is persistent mostly during the monsoon season. The NLLJ is frequent, unlike the SLLJ. The synoptic heat low in South Asia $\left(62^{\circ}-66^{\circ} \mathrm{E}\right.$ and $\left.27^{\circ}-32^{\circ} \mathrm{N}\right)$ and the anticyclone over Turkmenistan $\left(40^{\circ}-50^{\circ} \mathrm{N}\right.$ and $50^{\circ}-$ $60^{\circ} \mathrm{E}$ ) are critical in inducing the NLLJ. Regional topography permits direct mid-latitude air intrusion

*For correspondence. (e-mail: unnikrishnan.ck@ncess.gov.in) into the subtropical region. Importantly, we find that the NLLJ results in enhancing the transportation of dust to the Indian subcontinent and the northern part of the Arabian Sea due to wind blows. Long-term NLLJ intensity displays waning trend because of the weakening of pressure gradients between the heat low in South Asia and over Turkmenistan.

Keywords: Aerosol optical depth, low-level jet, regional hydrology, rainfall.

REGIONAL wind systems play a critical role in the climate and hydrology of an area ${ }^{1-3}$. The importance of low-level jets (LLJs) in impacting regional climate has been well recognized in many areas around the world ${ }^{4}$. The occurrence of regional wind patterns in Asia has an enormous consequence on oil exploration, agriculture and the economy of a region $^{5-7}$. The monsoon LLJ and Shamal wind over the Asian region have been well documented ${ }^{3,5,8}$. Previous studies suggest the existence of low-level northerly winds from June to September over Southwest Asia in the Iran-Afghanistan border area ${ }^{9,10}$. The northerly wind over Iran region is known as the Sistan wind or the "wind of 120 days" ${ }^{10}$. A recent study has examined the influence of Asian winds on the ecosystem in South Asia ${ }^{11}$. It also discusses about a Levar wind near the IranAfghanistan region reaching up to the northern part of the Arabian Sea. However, these studies are based on a dataset for a shorter period during the monsoon season. The analyses of 38-year multiple atmospheric reanalysis data showed two LLJ spells in the region, and we report them here as South Asian Subtropical LLJ (SASLLJ). The SASLLJ spells can be categorized into two types based on the direction as northerly and southerly (NLLJ and SLLJ respectively).

South Asia has relatively high population density, where freshwater availability mainly depends on the precipitation over the region. It has been recognized that even a small rainfall anomaly can influence the economy of South Asia ${ }^{12,13}$. Many regional winds influence the precipitation pattern and hydrology of the region ${ }^{1,14,15}$. On a different note, a study showed that aerosols from the Sahel region influence the Indian summer monsoon climate $^{16}$. In the present study, potential influence of the aforementioned wind patterns in West Asia, and its synoptic pattern on rainfall anomalies and aerosol transport into South Asia are examined. The study also analyses aerosol optical depth (AOD) as observed by the MODIS satellite ${ }^{17}$, which realized in understanding composite anomalies over South Asia.

Here we analyse the long-period characteristics of SASLLJs near the Iran-Afghanistan region using multiple reanalysis data. The role of SASLLJ synoptic conditions on regional hydrology and AOD over Asia is also examined. The long-term trend of SASLLJ intensity and its causes are presented. The European Centre for Medium-Range Weather Forecasts (ECMWF), the ERA 
RESEARCH COMMUNICATIONS
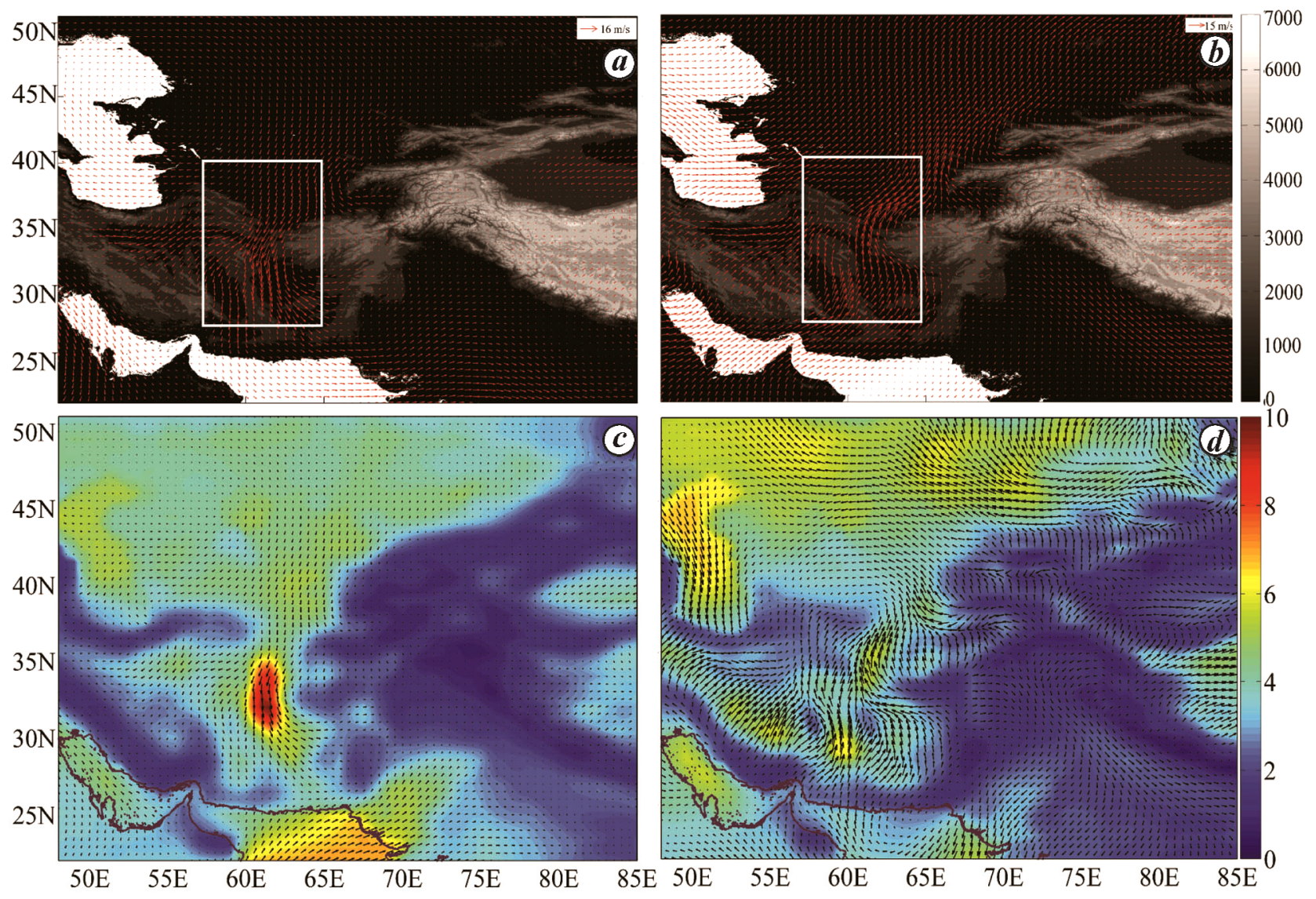

Figure $1 \boldsymbol{a}-\boldsymbol{d}$. Climatological $850 \mathrm{hPa}$ wind (top panel) and surface wind (bottom panel) in ERA Interim reanalysis. Northerly low-level jet (NLLJ; left panel) and southerly low-level jet (SLLJ; right panel). Wind speed is given in $\mathrm{ms}^{-1}$ and topography in $\mathrm{m}$.

Interim daily reanalysis, the National Oceanic and Atmospheric Administration (NOAA) Climate Forecast System reanalysis (CFSR), and the Tropical Rainfall Measuring Mission (TRMM) satellite rainfall data ${ }^{18}$ show that the aforesaid SASLLJ wind spells have been occurring over the study region analogous to that of the Shamal winds over the Arabian Peninsula ${ }^{9}$. Daily mean wind data between 1979 and 2016 were used for the study ${ }^{19}$. ECMWF data have been assimilated from the website: http://apps.ecmwf.int/datasets/data/interim-full-daily/ levtype $=$ sfc/. The NOAA CFSR data ${ }^{20}$ available from: https://www.ncdc.noaa.gov/data-access/model-data/modeldatasets/climate-forecast-system-version2-cfsv2 have also been collated. Both sets of data were resampled to a spatial resolution of $0.5^{\circ}$ for analysis.

LLJs are observed in many regions of the world; these strong winds are observed near the surface (between 1 and $2 \mathrm{~km}$ above the surface) with a speed greater than $12 \mathrm{~ms}^{-1}$. In this study, daily horizontal wind components greater than $12 \mathrm{~ms}^{-1}$ over a $31^{\circ}-35^{\circ} \mathrm{N}$ (lat.) and $60^{\circ}-62^{\circ} \mathrm{E}$ (long.) area are considered to identify the occurrence of LLJs. A total of 5729(605) northerly (southerly) LLJ days were identified during the period 1979-2016. We identified the core region of the jets through composite analysis. The composite analysis of precipitation and AOD datasets was also carried out. The wind convergence and vorticity were calculated at the $850 \mathrm{hPa}$ level to study the regional air convergence and rotational tendency respectively. The 3B42 daily rainfall from TRMM satellite (1998-2015) and MODIS satellite-observed daily AOD (MOD08_D3) during the period 2000-2016 have also been used in this study ${ }^{18}$.

Our composite long-period analysis of low-level winds over Southwest Asia revealed that periodic SASLLJs occurred throughout the year and the wind was persistent during the summer monsoon season. In the non-monsoon months, the wind was not continuous but occurred in spells. A consistently narrow NLLJ and a rare SLLJ wind pattern were observed over Southwest Asia. Strong northerly periodic SASLLJs were in the latitude and longitude box of $31^{\circ}-35^{\circ} \mathrm{N}$ and $60^{\circ}-62^{\circ} \mathrm{E}$ respectively, with a maximum mean wind speed of $17.67 \mathrm{~ms}^{-1}$ at $850 \mathrm{hPa}$. The climatological winds, derived from the 38 years ERA-Interim reanalysis (1979-2016), showed persistence of NLLJ at both $850 \mathrm{hPa}$ level and surface (Figure $1 a$ and $c$ ). The NLLJ core was observed at a pressure level of $850 \mathrm{hPa}$ (Figure $2 a$ and $c$ ). At $850 \mathrm{hPa}$, the wind reached up to the northern portion of the Arabian Sea and 


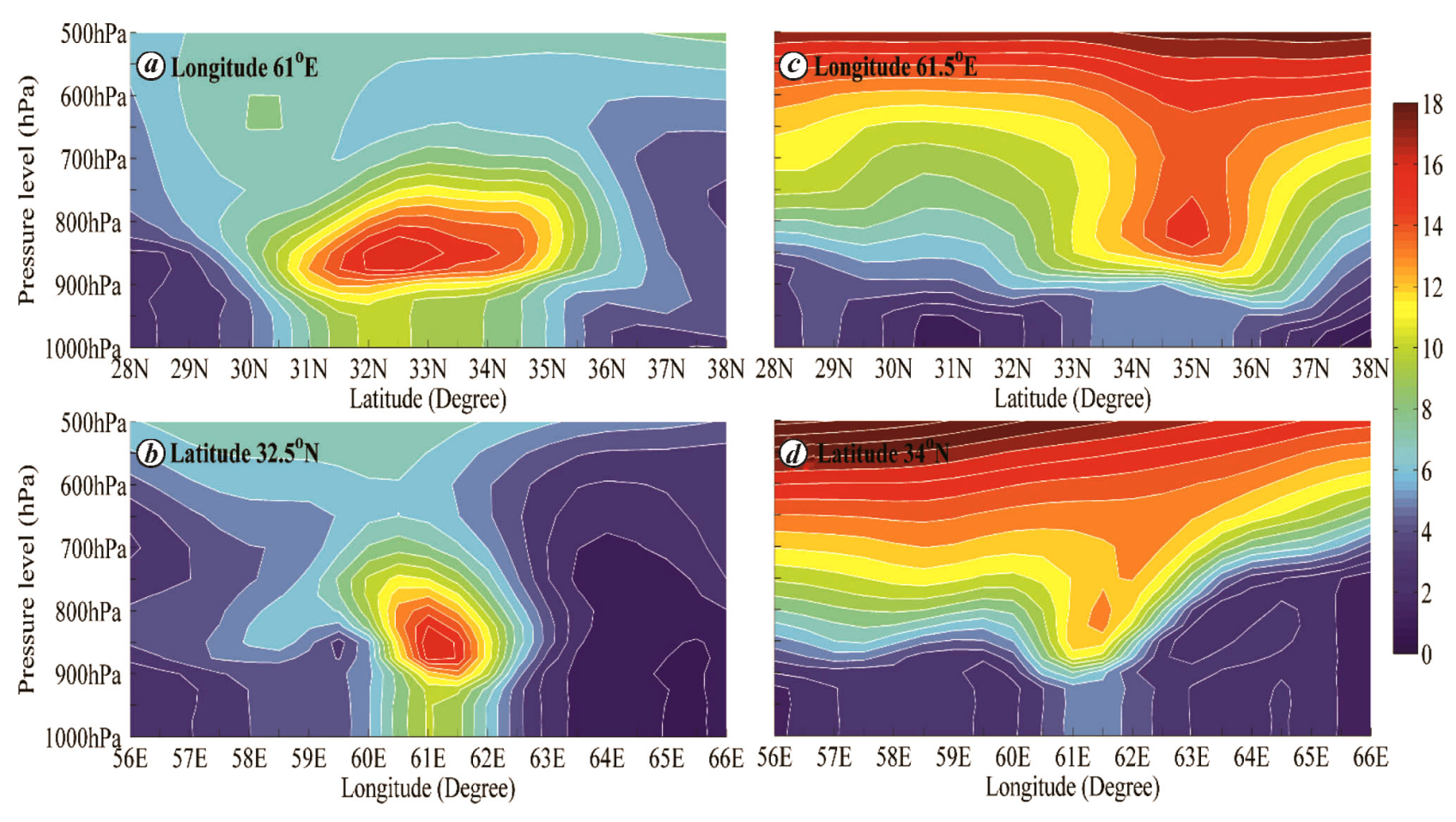

Figure 2. Composite of vertical profile of wind speed $\left(\mathrm{ms}^{-1}\right)$ : NLLJ (left panel) and Southerly SLLJ (right panel).

northwest India. However, the NLLJ was not visible at $500 \mathrm{hPa}$ or above. The mean (standard deviation) wind speed in the core region was $17.67 \mathrm{~ms}^{-1}\left(3.3 \mathrm{~ms}^{-1}\right)$. The wind flowed through Iran and Afghanistan, and extended up to Pakistan and India.

Figure 1 shows that this NLLJ transports the midlatitude air to subtropical South Asia. The SLLJ wind speed increases with elevation and its spatial spread increases towards the southern latitudes. This shows the influence of mountain ranges on the wind (Figure $1 a$ and $b$ ). Based on time-series analysis, the average duration of periodic NLLJ spells varied between 1 and 11 days in the non-monsoon months. The climatological wind analysis confirmed that NLLJ was geographically different from the periodic Shamal wind. Previous studies support the existence of northerlies and LLJ over $\operatorname{Iran}^{10,11}$. We observed that the mean wind pattern from CFSR is matching with ERA Interim analysis (Supplementary Figure 1).

The heat low over Iran and adjoining Pakistan that occurred during the pre-monsoon months of April and May was documented in previous South Asian monsoon studies $^{21,22}$. The heat low is observed over $62^{\circ}-66^{\circ} \mathrm{E}$ and $27^{\circ}-32^{\circ} \mathrm{N}$. This low is an important factor for the generation of winds during monsoon (Figure $3 c$ ), and shifts to Pakistan and northwest India in the monsoon period. However, heat low is not the only factor generating the SASLLJ. The anti-cyclone over Turkmenistan $\left(40^{\circ}-50^{\circ} \mathrm{N}\right.$ and $50^{\circ}-60^{\circ} \mathrm{E}$ ) is also essential for generating winds (Figure 3). It was reported that the Turkmenistan region registers a mid-level subsidence, which is favourable for the development of anticyclones ${ }^{23}$. Figure $3 c$ shows the composite surface pressure patterns of SASLLJ events from 1979 to 2016. The pressure gradient between anticyclones and lows was estimated; the pressure gradient and northerly (southerly) maximum LLJ wind speed exhibited a positive correlation of $0.33(0.38)$. Both correlations were significant at the 0.01 level. The pressure gradients of these synoptic lows and anticyclones along with topography generated the NLLJ. The dynamics of wind can be explained by Figure $3 e$ and through a backof-the envelope calculation applying the geostrophic wind equation (eq. (1)). The geostrophic terms in eq. (1) were calculated for NLLJ.

$$
f v=-\frac{1}{\rho} \frac{\partial p}{\partial x}
$$

where $f$ is the Coriolis parameter, $v$ the wind component, $\rho$ the density of air and $\partial p / \partial x$ is the pressure gradient.

In eq. (1), the calculated mean pressure gradient force between the low-pressure and high-pressure area is $0.011482 \mathrm{~N} \mathrm{~kg}^{-1}$ and the Coriolis force is $0.001 \mathrm{~N} \mathrm{~kg}^{-1}$. The calculated vector resultant wind flow is southward, with a flow that is $5^{\circ}$ westward. The calculated wind direction matches with the observation at the centre of the SASLLJ. Comparison of the pressure gradient term and Coriolis term according to eq. (1) shows that the NLLJ is not in geostrophic balance.

CURRENT SCIENCE, VOL. 117, NO. 5, 10 SEPTEMBER 2019 


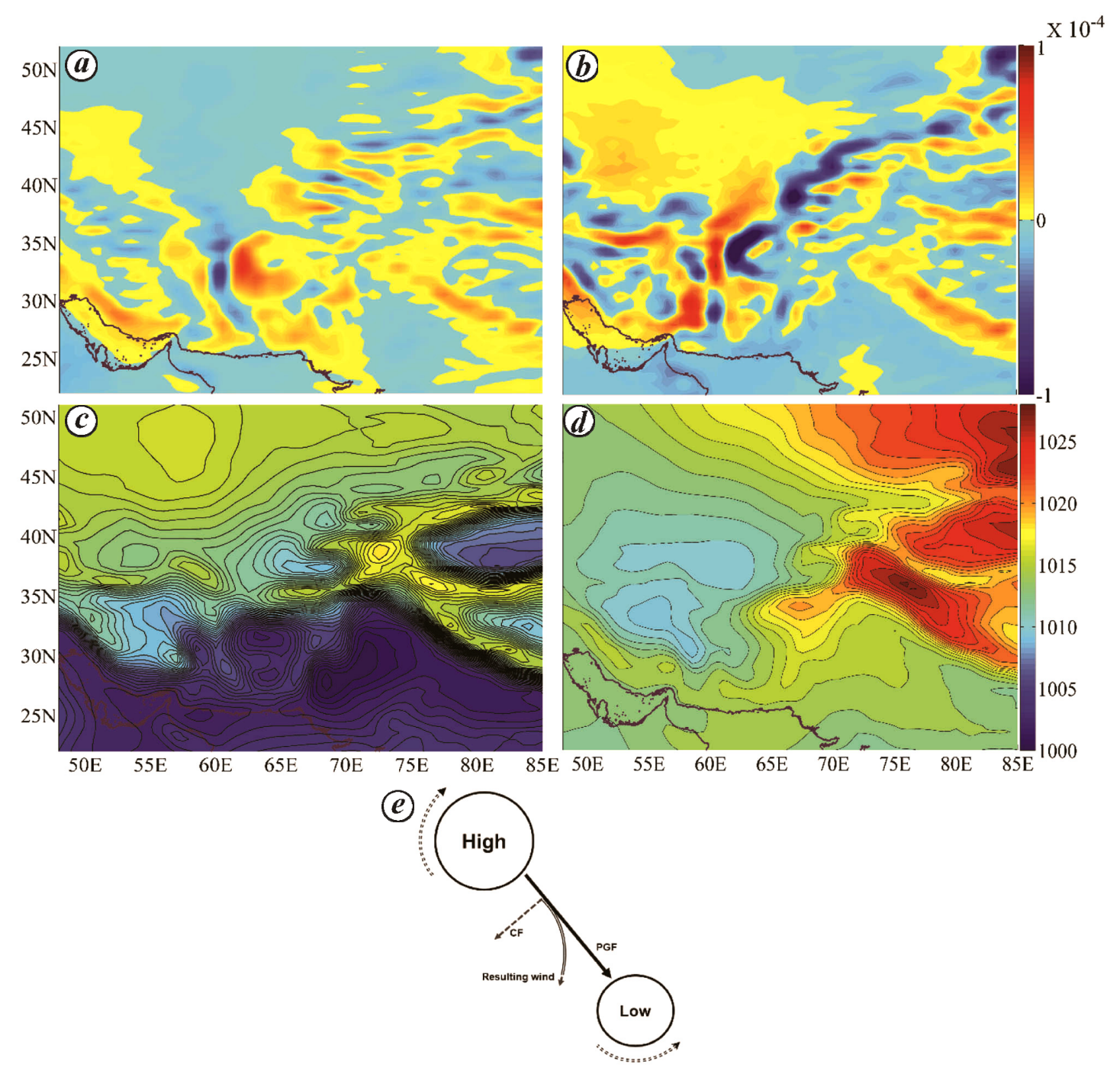

Figure 3. Composite of relative vorticity $\left(\mathrm{s}^{-1}\right)$ (top panel) and surface pressure (hPa) (bottom panel): (a, c) NLLJ and (b, d) SLLJ. $\boldsymbol{e}$, Schematic representation of dynamics of NLLJ.

The temperature advection from northern mid-latitudes during the NLLJ episodes is reaching southward up to $28^{\circ} \mathrm{N}$. After $28^{\circ} \mathrm{N}$ lat., the SASLLJ is well mixed with subtropical air. The wind-induced westerlies in northwest India impart a positive vorticity to the Himalayan region (Figure $3 a$ ). The induced westerly winds and synoptic conditions support the vertical movement of air in the Himalaya and hence enhance cloud development in the region.

The TRMM satellite rainfall data were used to study (1998-2015) the influence of wind pattern on regional hydrology. The composite rainfall pattern during the NLLJ period indicates that the Indian Himalayan region, except the northwest desert region, has a positive rainfall anomaly. The existence of low pressure attracts the moisture-rich southerly surface winds from the Arabian Sea (Figure $1 c$ ) resulting in rainfall over the Himalaya (Figure $4 a$ and $c$ ). The surface wind touches the northern
Arabian Sea and transports moisture to northern and northwest India. The resultant cyclonic wind pattern around the low-pressure region enhances the transport of moisture from the North Arabian Sea to the Himalaya. During the NLLJ period, the southern portion of the Iranian mountain range is on the leeward side and causes negative rainfall anomaly over the region.

The SLLJ spells observed over the region were opposite to the NLLJ (Figure $1 b$ ). Lower topography as well as location of the low pressure and anticyclone over the region generate SLLJs (Figures $1 b$ and $d$ and $3 d$ ). The SLLJ wind has not yet been systematically studied. The occurrence of SLLJ is rarely compared to the NLLJ. The mean (standard deviation) SLLJ speed in the core region was $14.9 \mathrm{~ms}^{-1}\left(2.4 \mathrm{~ms}^{-1}\right)$ during the period 19792016. Figure $2 b$ and $d$ shows that the wind core is located at $850 \mathrm{hPa}$. The average duration of periodic SLLJ spells varies between 1 and 4 days. Figure $3 b$ and $d$ shows the 

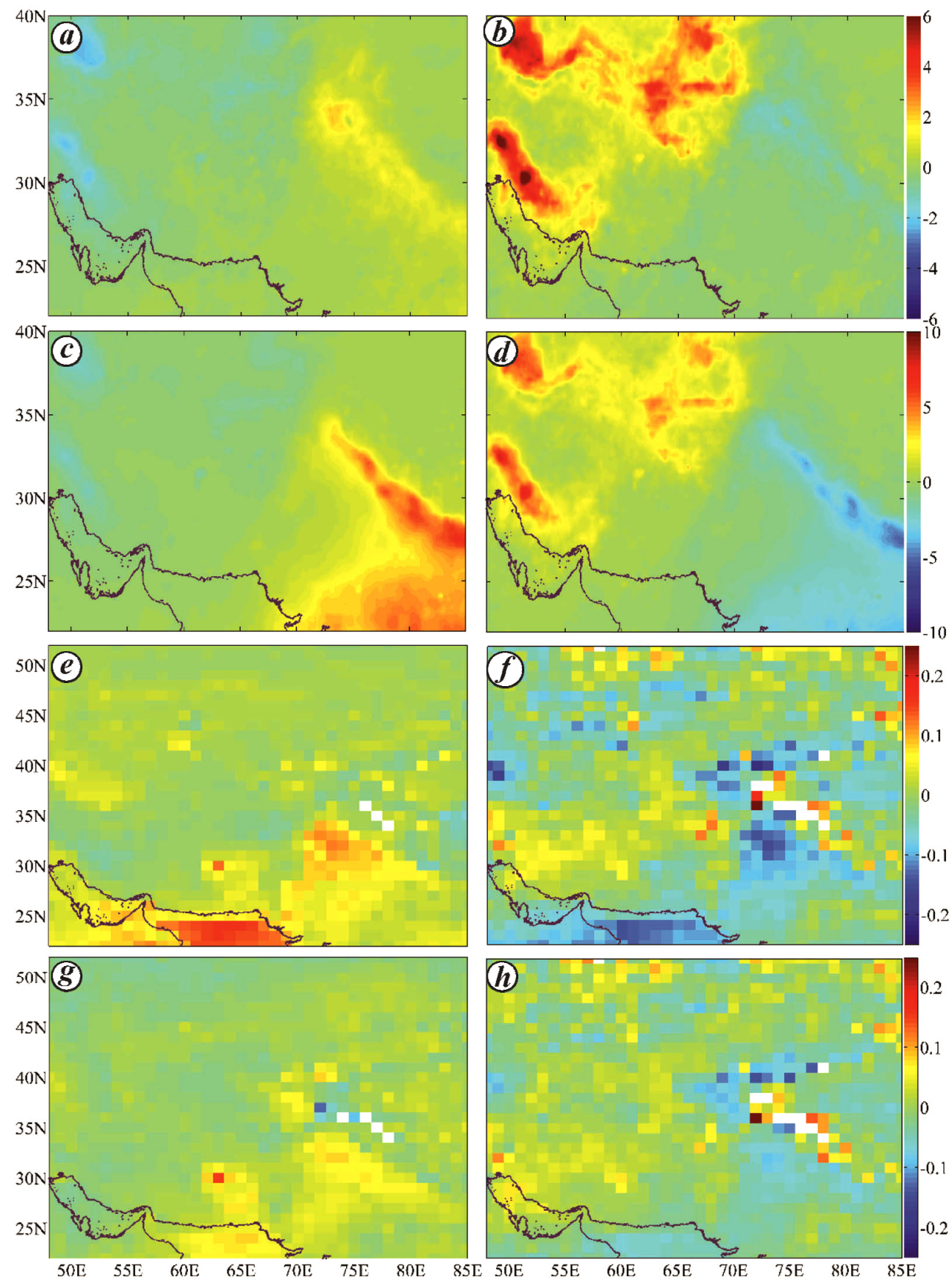

Figure 4. Composite rainfall anomalies and aerosol optical depth (AOD) anomalies during the occurrence of South Asian subtropical low-level jets. Rainfall anomaly (cm): $\boldsymbol{a}$, NLLJ (non-monsoon months); $\boldsymbol{b}$, SLLJ (non-monsoon months); $\boldsymbol{c}$, NLLJ (all events); $\boldsymbol{d}$, SLLJ (all events). AOD anomaly; $\boldsymbol{e}$, NLLJ (all events); $\boldsymbol{f}$, SLLJ (all events); $\boldsymbol{g}$, NLLJ (non-monsoon events); $\boldsymbol{h}$, SLLJ (non-monsoon events).

vorticity patterns and surface pressure of wind respectively. The low pressure to the west of SASLLJ and high pressure to its east generate the opposite southerly wind. The precipitation pattern is complementary to the NLLJ rainfall anomaly (Figure $4 b$ and $d$ ). The windward mountain ranges in Iran and the northern latitudes receive precipitation during the SLLJ. The Himalayan precipitation displays a negative anomaly during the SLLJ period. Dur- ing the SLLJ wind events, moisture-rich winds from the Persian Gulf move over the southern side of the mountain ranges in Iran, resulting in rainfall over the region (Figure $1 b)$.

The MODIS satellite AOD composite analysis (Figure $4 e$ and $g$ ) shows that the NLLJ events contribute positively to AOD in North India. The wind pattern (Figure 1) and a previous case study by Najafi et al. ${ }^{24}$ support this 
result, wherein the authors illustrated that the northerly winds persistently transport dust and desert dry air to North India, northern portion of the Arabian Sea, and the adjoining region. A negative AOD anomaly is observed in the northern portion of the Arabian Sea and northwest India during the SLLJ events (Figure $4 f$ and $h$ ).

Furthermore, intensity changes of the SASLLJ during recent decades have been examined. The long-term trend of the NLLJ has been analysed using the Mann-Kendall trend test. The average northerly LLJ daily wind speed exhibited a significant (0.01) negative trend (-0.016) during the study period. No significant trend was observed for the number of NLLJ days in a year. Meanwhile, the average pressure gradient between low pressure and high pressure showed a significant (0.01) decreasing trend $(-0.037)$. The monsoon low showed a significant (0.05) increase in surface pressure over the low area (0.022). The average high pressure over the anticyclone region registered a decreasing trend $(-0.013)$; however, the trend was not significant. Overall, a negative trend in the pressure gradient between high pressure and low pressure was found to influence the NLLJ core intensity. We conclude that this NLLJ is to some extent weakening in its intensity over the study period. Whereas the SLLJ intensity did not show any significant $(0.05$ level $)$ trend during the same period.

A strong northerly and southerly periodic LLJ was noticed over subtropical South Asia, with core at the $850 \mathrm{hPa}$ level and jet core located between $31^{\circ}-35^{\circ} \mathrm{N}$ and $60^{\circ}-62^{\circ} \mathrm{E}$. A combination of the anticyclone over Turkmenistan, low pressure in South Asia, and the regional orography activated the NLLJ. The wind climatology corroborates that the NLLJ persistently transports the midlatitude air to South Asia during the monsoon months. Similarly, the SLLJ transports the near-surface subtropical air mass to the mid-latitudes in Asia. The wind was observed from the surface to $700 \mathrm{hPa}$. The low pressure and high pressure responsible for generating the SLLJ were located to its west and east respectively.

The NLLJ and its synoptic condition promote rainfall activity over the Himalaya and the Indian region; however, they suppress rainfall over the Arabian Peninsula. The vorticity pattern suggests that the wind and its synoptic conditions impart positive vorticity to the Himalaya and promote cloud formation over the region. The enhancement in moisture-rich surface winds from the Arabian Sea supports cloud formation in Central India and the Himalaya. Our result shows that wind circulation transports dust to the northern portion of the Arabian Sea and North India to enhance AOD over the regions. The SLLJ event shows an opposite anomaly for rainfall as well as for AOD over the study region. The SLLJ events suppress rainfall over the Himalaya co-terminus with a negative AOD anomaly in the northern Arabian Sea and North India. NLLJ has been weakening in recent periods because of weakening of the pressure gradient between the heat low in South Asia and the anticyclone over Turkmenistan.

Bollasina and Nigam ${ }^{25}$ hypothesized that wind from the Elburz-Zagros-Hindu Kush Mountains contributes to the monsoon heat low intensity in June and July. Our results on the NLLJ support the above hypothesis ${ }^{25}$. It has been documented that mid-latitude intrusions influence rainfall in the South Asia monsoon ${ }^{26}$. Further scope exists to study the role of these winds on intra-seasonal monsoon variability in order to bring out the finer details of midlatitude intrusions. The role of wind and dust transportation on cloud microphysics, rain formation, regional visibility and contribution to pollution levels needs to be understood further. Our study lends credence to consider that the northerly low-level winds reaching up to the Arabian Sea influence the surface wave pattern and primary productivity in the Arabian Sea. A recent study illustrated that the NLLJ influences wave pattern in the northern portion of the Arabian $\mathrm{Sea}^{27}$.

1. Joseph, P. V. and and Sijikumar, S., Intraseasonal variability of the low-level jet stream of the Asian summer monsoon. J. Climate, 2004, 17, 1449-1458.

2. Zou, H. et al., Local wind system in the Rongbuk Valley on the northern slope of Mt. Everest. Geophys. Res. Lett., 2008, 35, L13813.

3. Yu, Y., Notaro, M., Kalashnikova, O. V. and Garay, M. J., Climatology of summer Shamal wind in the Middle East. J. Geophys. Res. Atmos., 2016, 121, 289-230.

4. Stensrud, D. J., Importance of low-level jets to climate: a review. J. Climate, 1996, 9, 1698-1711.

5. Membery, D. A., Low level wind profiles during the Gulf Shamal. Weather, 1983, 38, 18-24.

6. Gadgil, S., The Indian monsoon and its variability. Annu. Rev Earth Planet. Sci., 2003, 31(1), 429-467.

7. Gadgil, S. and Gadgil, S., The Indian monsoon, GDP and agriculture. Econ. Polit. Wkly., 2006, 41(47), 4887-4895.

8. Findlater, J., A major low-level air current near the Indian Ocean during the northern summer. Q. J. R. Meteorol. Soc., 1969, 95, $362-380$.

9. Liu, M., Westphal, D. L., Holt, T. R. and Xu, Q., Numerical simulation of a low-level jet over complex Terrain in Southern Iran. Mon. Weather Rev., 2000, 128, 1309-1327.

10. Alizadeh-Choobari, Zawar-Reza, P. and Sturman, A., The 'wind of 120 days' and dust storm activity over the Sistan Basin. Atmos. Res., 2014, 143, 328-341.

11. Ramaswamy, V., Muraleedharan, Babu, P. M. and Prakash, C., Mid-troposphere transport of middle-east dust over the Arabian sea and its effect on rainwater composition and sensitive ecosystems over India. Sci. Rep., 2017, 7, 1-8.

12. Gadgil, S., The Indian monsoon - how do we get rain? Resonance, 2006, 11, 8-21.

13. Lau, W. K. M., Waliser, D. E. and Goswami, B. N., South Asian monsoon. In Intraseasonal Variability in the Atmosphere-Ocean Climate System, Springer Praxis Books, Springer, Berlin, Germany, 2012, pp. 21-72.

14. Neiman, P. J., Ralph, F. M., White, A. B., Kingsmill, D. E. and Persson, P. O., The statistical relationship between upslope flow and rainfall in California's coastal mountains: observations during CALJET. Mon. Weather Rev., 2002, 130, 1468-1492.

15. Panziera, L. and Germann, U., The relation between air flow and orographic precipitation on the southern side of the Alps as 
revealed by weather radar. Q. J. R. Meteorol. Soc., 2010, 136, $222-238$.

16. Vinoj, V., Rasch, P. J., Wang, H., Yoon, Jin-Ho, Landu, K., Singh, B. and Ma, Po-Lun, Short-term modulation of Indian summer monsoon rainfall by West Asian dust. Nature Geosci., 2014, 7, 308-313.

17. Platnick, S. et al., MODIS Atmosphere L3 Daily Product. NASA MODIS Adaptive Processing System, Goddard Space Flight Center, USA, 2015; http://dx.doi.org/10.5067/MODIS/MOD08 D3.006.

18. Huffman, G. J. et al., The TRMM Multisatellite Precipitation Analysis (TMPA): quasi-global, multiyear, combined-sensor precipitation estimates at fine scales. J. Hydrometeorol., 2007, 8, 38 55.

19. Dee, D. P. et al., The ERA-interim reanalysis: configuration and performance of the data assimilation system. Q. J. R. Meteorol. Soc., 2011, 137, 553-597.

20. Saha, S. et al., The NCEP climate forecast system reanalysis. Bull. Am. Meteorol. Soc., 2010, 91, 1015-1057.

21. Rao, Y. P., Meteorological Monograph Synoptic Meteorology, No. 1/1976: South West Monsoon, India Meteorological Department, 1979, pp. 1-379; http://imdpune.gov.in/Weather/Reports/sw\%20 monsoon\%20whole\%20book.pdf

22. Pant, G. and Kumar, K., Climates of South Asia, John Wiley, Hoboken, NJ, USA, 1997

23. Tyrlis, E., Lelieveld, J. and Steil, B., The summer circulation over the eastern Mediterranean and the Middle East: influence of the South Asian monsoon. Climate Dyn., 1997, 40, 1103.

24. Najafi, M. S., Sarraf, B. S. and Zarrin, A., Climatology of atmospheric circulation patterns of Arabian dust in western Iran. Environ. Monit. Assess., 2017, 189, 473.

25. Bollasina, M. and Nigam, S., The summertime 'heat' low over Pakistan/Northwestern India: evolution and origin. Climate Dyn., 2011, 37, 957-970.

26. Krishnan, R., Kumar, V., Sugi, M. and Yoshimura, J., Internal feedbacks from monsoon-midlatitude interactions during droughts in the Indian summer monsoon. J. Atmos. Sci., 2009, 66(3), 553-578.

27. Anoop, T. R. et al., On the generation and propagation of Makran swells in the Arabian Sea. Int. J. Climatol., 2019, 1-9.

ACKNOWLEDGEMENTS. We thank the following data sources: ECMWF ERA Interim, NOAA CFSR, NASA MODIS AOD and TRMM rainfall product. This study was supported by the Ministry of Earth Sciences, Government of India. We thank the Director, National Centre for Earth Science Studies, Thiruvananthapuram for encouragement and support.

Received 17 September 2018; accepted 20 June 2019

\section{Boron measurement in tourmaline from pegmatite veins, Simdega area, Chhotanagpur Gneissic Complex, Eastern India using Electron Probe Microanalysis}

\author{
Deepak Kumar, Dinesh Pandit, Abhinay Sharma \\ and N. V. Chalapathi Rao*
}

Mantle Petrology Laboratory, Department of Geology,

Centre of Advanced Study, Institute of Science,

Banaras Hindu University, Varanasi 221 005, India

Tourmaline group of minerals, the primary source of boron, are cyclosilicates which are widespread in the earth's crust. Earlier studies involving the nomenclature and classification of tourmaline were based on the measurement of its common elements (Al, Mn, Fe, $\mathrm{Mg}$, etc.). In all such studies, boron was assumed to be fixed in the composition and restricted only to the triangular structural site. However, recent discovery of the presence of boron in the tetrahedral structural site as well, necessitates the measurement of boron content. Much of the earlier attempts to measure boron were based on solution methods, and electron microprobe analysis (EPMA) was the least used due to low levels of detection of its analytical crystals. In the present study, we quantify boron - particularly along with fluorine and other major elements - in tourmaline grains using high-sensitivity PC3 analytical crystal. We found that the measured boron content slightly exceeds that of the stoichiometrically calculated boron. Also, the studied tourmalines come under the alkali group in general and belong to the schorldravite solid solution series in particular.

Keywords: Boron, electron probe micro analysis, pegmatite, tourmaline.

TOURMALINE group of minerals are cyclosilicates with significant amount of boron and are widespread in the earth's crust. Tourmaline is regarded as a good indicator for understanding the crustal evolution because its paragenesis extends to a wide range of physico-chemical fields and can constitute a petrological indicator ${ }^{1-3}$. Being a chemically and mechanically resistant mineral, its occurrence in clastic sedimentary rocks is common ${ }^{4,5}$. Tourmaline can also form during the late stage of diagenesis $^{6-9}$. It can be related to two completely miscible solid solution series: schorl-dravite and schorl-elbaite. Some common end-members in the tourmaline group include schorl, dravite, elbaite, tsiliasite, uvite, liddicoatite, alkali-defect tourmaline, proton-deficient tourmaline, buergerite and ferridravite ${ }^{10}$.

*For correspondence. (e-mail: nvcrao@bhu.ac.in) 